\title{
A Comparative Study To Assess The Knowledge On Pregnancy Induced Hypertension Among Cases And Control Antenatal Mothers Attending Antenatal OPD at MGMCRI ,Puducherry.
}

\author{
*Lavanya.S, ** Anitha.B, ${ }^{* * *}$ Annie Annal.M
}

\begin{abstract}
:
Objectives: To assess the knowledge on pregnancy induced hypertension among cases and control. To compare the knowledge on pregnancy induced hypertension among cases and control. Materials and Methods of Study: Descriptive Research Design was used. Results: The findings of the study revealed that mean Knowledge score of Cases was higher than mean score of Control Group. Thus the difference in the level of knowledge was found to be significant at $p<0.001$ level. There was significant difference between cases and control group.Conclusion: This Study concluded that the mothers with history of pregnancy induced hypertension had adequate knowledge about the condition.
\end{abstract}

Keywords: Pregnancy Induced Hypertension, Cases, Control.

\section{INTRODUCTION}

Pregnancy and child birth is considered as normal physiological process. Pregnancy is most memorable moment in a woman's life. However, many medical disorders can complicate this memorable moment and the leading one is Pregnancy Induced Hypertension (PIH). PIH is more common in mother of age more than 35 years with multiple pregnancy and obesity as well as in women from low socio economic background. $\mathrm{PIH}$ is characterized by hypertension and protein urea accompanied by oedema, which affect both foetus and mother adversely. ${ }^{1}$

Hypertension is one of the common complications met with pregnancy and contributes significantly to maternal and perinatal morbidity and mortality.
Hypertension is a sign of an underlying pathology which may be preexisting or appears for the first time during pregnancy. The identification of this clinical entity and effective management play a significant role in the outcome of pregnancy, both for mother and the baby ${ }^{2}$.

The incidence of Pregnancy Induced Hypertension in India is 30-40 percent of all pregnancy, in Tamil Nadu it is 40 percent and in Puducherry 10-18 percent.

Hypertensive disorders of pregnancy are leading cause of maternal and infant mortality and morbidity. World-wide, it has been estimated that approximately 50,000 women die every year from eclampsia. Hypertensive disorders of pregnancy affect $5-10 \%$ of all pregnancies, world-wide, and cause substational perinatal mortality and 
morbidity. Women with Pre-eclampsia are 2 to 3 times more likely to have Caesarean delivery compared to normotensive women and have longer hospital stay. The combined prevalence, of various hypertensive disorders in pregnancy, is said to be of 6-8\%, which are the leading causes of maternal and perinatal mortality and morbidity . Interventions during pregnancy, may improve maternal outcomes. In this regard, the intervention includes primary prevention, detection of increased risk and early detection of any stage of PIH by antenatal adequate care. Secondary prevention of progression is by treatment at primary level or referral for expert care .Caring of a primi gravida with ecalmpsia is a challenge to any midwife. The midwife's keen observation, prompt decision-making-ability to use life saving procedures and referral to the right place, at the right time, can save the mother and the baby. The mother requires intensive care with continuous monitoring and recording the baby also needs close observation and care, for the first 24-48 hours, in the neonatal intensive care unit .

\section{Statement Of The Problem:}

"A Comparative Study To Assess The Knowledge On Pregnancy Induced Hypertension Among Cases And Control Antenatal Mothers Attending Antenatal OPD At MGMCRI, Puducherry".

\section{Objectives Of The Study:}

1. To assess the knowledge on pregnancy induced hypertension among cases and control.

2. To compare the knowledge on pregnancy induced hypertension among cases and control.

\section{Materials And Methods}

Research Approach: survey approach was used in the study.

Research Design: The descriptive research design was used in the study

Study Setting: The study was conducted in Antenatal OPD MGMC\&RI ,Pillayarkuppam.

Study Population: The target population for the study was Antenatal mothers with and without pregnancy induced hypertension.

\section{Sample Size:}

Totally 40 samples were selected. Group I comprised of 20 antenatal mothers diagnosed with pregnancy induced hypertension. Group II comprised of 20 antenatal mothers not diagnosed with pregnancy induced hypertension.

\section{Sampling Technique:}

The samples were selected by using Nonprobability Purposive sampling technique.

\section{Criteria for Sample Selection:}

\section{Inclusion Criteria:}

The study includes,

- Antenatal mothers diagnosed with PIH.

- Antenatal mothers not diagnosed with PIH.

- Interested to participate in the study

- Understand Tamil and English.

\section{Exclusion Criteria:}

The study excludes,

- Not Interested to participate in the study

- Not Understand Tamil and English. 
RESULTS

Level of knowledge on Pregnancy Induced Hypertension among cases and control antenatal mothers.

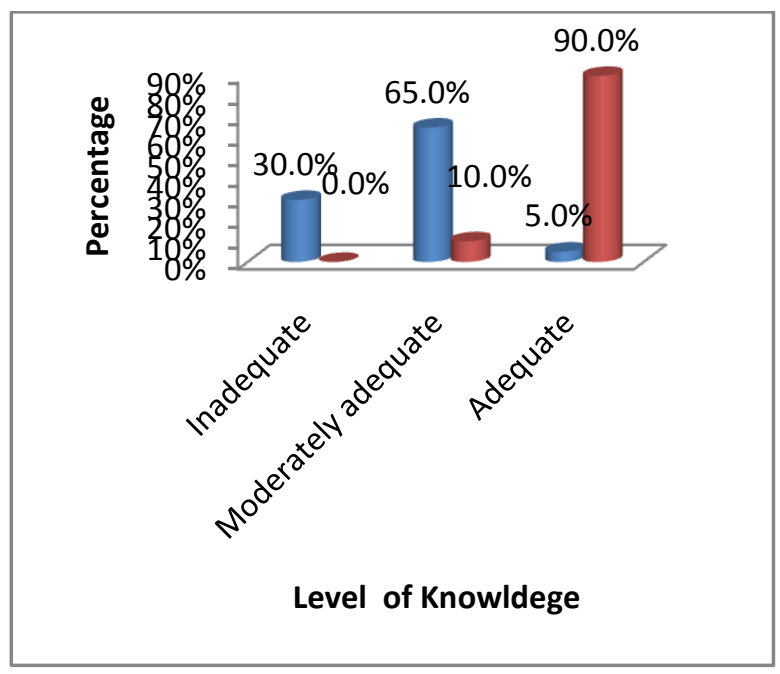

In cases ,Majority of the samples 18(90\%) had adequate knowledge , 2(10\%) had moderately adequate knowledge, no one had inadequate knowledge. In control group 1(5\%) had adequate knowledge , 13(65\%) had moderately adequate knowledge, $6(30 \%)$ had inadequate knowledge. This shows that mothers with history of pregnancy induced hypertension had adequate knowledge about the condition.

\section{Comparison of Mean and Standard}

Deviation between cases and control group.

\begin{tabular}{|l|l|l|l|l|}
\hline Group & SD & \multicolumn{1}{|c|}{ t-test } & $\begin{array}{l}\text { P } \\
\text { value }\end{array}$ \\
\hline Cases & 16.45 & 1.82 & -7.427 & $<0.001$ \\
\hline Control & 11.15 & 2.621 & & \\
\hline
\end{tabular}

The findings of the study revealed that mean Knowledge score of Cases was higher than mean score of Control Group. Thus the difference in the level of knowledge was found to be significant at $\mathrm{p}<0.001$ level. There was significant difference between cases and control group.

\section{CONCLUSION:}

The study was done to determine the level of knowledge on Pregnancy Induced Hypertension among antenatal mothers who had been diagnosed with Pregnancy Induced Hypertension and Antenatal mothers without Pregnancy Induced Hypertension. The study findings provided the statistical evidence which clearly indicated that the antenatal mothers who have history of Pregnancy Induced Hypertension have adequate knowledge about the condition.

\section{REFERENCES:}

1. Muhammed Safvan, Namitha B.R, et al. The knowledge on prevention of pregnancy induced hypertension among antenatal mothers: a descriptive approach. Pakistan Journal of Social Sciences. 2010 . Available from:http://www.recentscientific.com/knowl edge-prevention-pregnancy-inducedhypertension-among-antenatal-mothersdescriptive-approah.

2. V. Ruth Bennent, Lindak. Brown., (1993). "Myles Text Book for Midwives Churchill Living”. (12th Edition), 310-317.0

3. D.C. Dutta. Textbook of Obstetrics $5^{\text {th }}$ Ed. New central book. Agency (P) Ltd ; Calcutta ; $1983 ; 234$.

4. Global Monitoring Report. By World Bank; 2007 hhp://web;world Bank.org/2007/0.com. 
6. Diane M.Fraser and Margaret A Cooper. Textbook for Midwives. 14th Ed. Churchill: Elsevier Limited; 2003; 357.

7. Maternal HH. www.ceeindia.org/mdgs/goal20055hmt-18k.

8. Oyira Emilia James, Mary A. Mgbekem and Okon Abigail Edem . Knowledge, Attitude and Preventive Practices Towards Pregnancy Induced Hypertension among Pregnant Women in General Hospital Calabar,. Pakistan Journal of Social Sciences. 2009. 6:pp 1-5.

9. Prakash J. Hypertension in pregnancy; Hospital based study J Assoc Physicians India 2006, Apr ; 54 ; $273-8$.

10. Jutiana Linnethe D'sa. Evaluation of a Problem Based Learning Package on Pregnancy - Induced Hypertension for B.Sc. Nursing students. The Nursing Journal of India, November 2002 Vol, LXXXXIII, No. 11: 261.

\section{6-PS OF DYSPNEA}

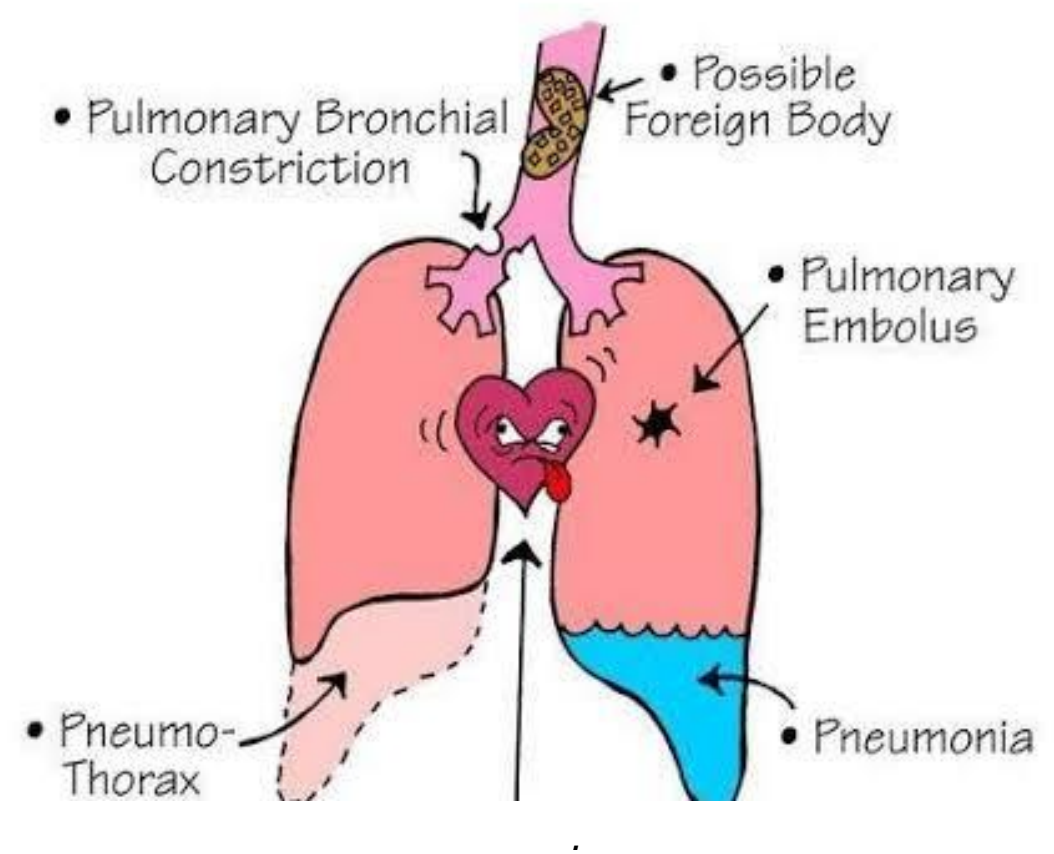

